\title{
Leaf Color and Growth Change of Sedum rubrotinctum Caused by Two Commercial Chemical Products
}

\author{
Ying Ma \\ Forestry College, Central South University of Forestry and Technology, \\ Changsha, 410004, People's Republic of China
}

\author{
Xinduo Li \\ Aromatic Plants Research Institute, Forestry College, Central South \\ University of Forestry and Technology, Changsha, 410004, People's \\ Republic of China
}

\section{Zhanying Gu}

The Key Lab of Cultivation and Protection for Non-Wood Forest Trees of Education Ministry, Central South University of Forestry and Technology, Changsha, 410004, People's Republic of China

\section{Jian'an $\mathbf{L i}^{1}$ \\ The Key Lab of Non-wood Forest Products of State Forestry Administration, Central South University of Forestry and Technology, Changsha, 410004, People's Republic of China}

Additional index words. chlorophyll content, chromaticity, ornamental value, pigment, succulent

\begin{abstract}
Sedum rubrotinctum is widely grown as an ornamental because of its attractive leaf shape and color. Increasing the morphological diversity and color will greatly add to its ornamental value. Environmental conditions such as light and temperature can change the leaf color of succulent plants, but the mechanism is uncertain. To examine this mechanism, we tested the effects of two commercial chemical products Sowing Goodliness (Sg) and Aromatic Garden (Ag) on the morphology, pigment content, and growth performance of Sedum rubrotinctum seedlings. The Sg treatment did not change foliage color, but can accelerate plant growth and increase lateral bud number. The Ag treatment had marked changes on the relative proportions of pigments and leaf color, and plant growth was severely reduced with mortality observed in some plants. After Ag stress was discontinued, the surviving plants began to regrow and had good ornamental value but had the fewest number of lateral buds and leaves, and the smallest leaf length and thickness, canopy diameter, and plant height. Foliage color changes are caused directly by shifts in the relative proportions of pigments, particularly chlorophyll $b$ and anthocyanin. In Ag-treated plants, chlorophyll b declined much faster than chlorophyll a, indicating that the transformation of chlorophyll $b$ into chlorophyll $a$ is an important step in the chlorophyll degradation pathway. Ag provides a way to learn more about the mechanism of chlorophyll degradation and should be investigated further. Ag enhanced anthocyanin production rapidly and improved the ornamental value of Sedum rubrotinctum. Different concentrations of $\mathrm{Ag}$ and $\mathrm{Sg}$ were not studied in this trial and might be tested to determine the ideal balance between leaf color and plant growth.
\end{abstract}

\footnotetext{
Received for publication 7 Sept. 2018. Accepted for publication 5 Jan. 2019.

This study was funded by the Hu'nan Educational Committee Foundation, China (16B278) and supported in part by the Key Laboratory of Non-Wood Forest Products, the State Forestry Administration, the Aromatics Research Institute of the Central South University of Forestry and Technology, and the Yixinyi Horticultural Plants Company (China). We sincerely appreciate the hard work of all the editors.

${ }^{1}$ Corresponding author: E-mail: lja0731@126.com. This is an open access article distributed under the CC BY-NC-ND license (https://creativecommons. org/licenses/by-nc-nd/4.0/).
}

Sedum rubrotinctum is a perennial member of the family Crassulaceae. It is native to the arid regions of northeastern Mexico. This species is grown for ornamental purposes in many places around the world because of its attractive leaf shape and color. The leaves are fleshy, alternately arranged, cylindrical, green, and do not have a superficial white powder coating. Potted sedum plants are used for ornamental purposes. The species is also used in landscaping rock gardens, roof gardens, and as a groundcover in the corners of garden plots.
The leaves of $S$. rubrotinctum change color with changes in environmental conditions. The color changes add to the ornamental value of the plant. Low temperature and high light intensity induce changes in leaf color, which is normally green. The underlying factors responsible for changes in leaf color have not been examined in detail. Supplemental lighting has been tested as a mechanism for changing leaf color, but this approach requires the installation of extensive electrical hardware. Foliar sprays containing sugar or nanoparticles reportedly increased anthocyanin content in plants (Hu et al., 2016), but the procedure has not been tested on succulents.

Leaf color is determined by the proportions of chlorophylls, carotenoids, and anthocyanins (Abbott, 1999). The color intensity of red senescing leaves is increased by high light, cool temperature, and mild drought during the period of anthocyanin synthesis that precedes chlorophyll breakdown (ChalkerScott, 1999; Dodd et al., 1998)

Secondary metabolites, referred to as secondary products or natural products, are organic compounds. They are not directly involved in plant growth, development, or reproduction. They do not directly participate in respiration, translocation, protein synthesis, nutrient assimilation, photosynthesis, or differentiation. However, the absence of secondary metabolites may result in long-term impairment of the plant's survivability, and even in immediate death. These compounds generally include pigments, antitumor agents, effectors of ecological competition and symbiosis, and molecules of plant chemical defense (Bartwal et al., 2013). Secondary metabolites are generally widely distributed at low concentrations in living organisms (Ouzounis et al., 2015). Their role in plant stress physiology is indisputable. A plant's defense strategies involve a vast variety of secondary metabolites serving as tools to overcome stress constraints, adapt to the changing environment, and thus help in survival under suboptimal conditions (Edreva et al., 2008).

Chlorophyll harvests impinging photons in a mechanism that enables the conversion of $\mathrm{CO}_{2}$ into energy-rich sugars, which are used in a vast range of plant metabolic processes (Forney et al., 2000; Xu, 2013). The structures of chlorophyll $a$ and $b$ differ only in the third carbon position (Von Wettstein et al., 1995), which affects their light-absorbing properties. Chlorophyll a is present in all photosynthetic organisms. It absorbs light in the blue, red, and violet portions of the visible spectrum. Chlorophyll a reflects green light, hence the green color of leaves. Chlorophyll a plays a major role in oxygenic photosynthesis, which produces molecular $\mathrm{O}_{2}$ as a main by-product. Among eukaryotes, chlorophyll b occurs in green plants and green algae. It also occurs in one group of Cyanobacteria, the Prochlorales. Chlorophyll $b$ has absorption peaks that differ from those of chlorophyll a. 
Organisms with both chlorophyll $\mathrm{a}$ and $\mathrm{b}$ pigments absorb across a broad range of blue and red light.

Carotenoid pigments are synthesized by many photosynthetic and nonphotosynthetic organisms (e.g., plants, bacteria, and fungi). Carotenoids absorb light between 460 and $550 \mathrm{~nm}$. They appear orange, red, and yellow in color. Carotenoids absorb light energy for use in photosynthesis, and they protect chlorophyll from photodamage (Armstrong and Hearst, 1996).

Anthocyanins are water-soluble pigments that produce the red, purple, and blue coloration of many flowers and fruits (Shang et al., 2011). Anthocyanin accumulation is stimulated by diverse environmental stresses, such as ultraviolet radiation, blue light, highintensity white light, wounding, pathogen attack, drought, sugar, and nutrient deficiencies (Winkel-Shirley, 2001). By absorbing light in the visible range, anthocyanin protects photosynthetic tissues from excessive solar radiation. It also functions as an antioxidant that protects the physiological status of plant tissues directly or indirectly exposed to biotic or abiotic stressors. When plants are stressed, production of these secondary metabolites may increase. Stress often affects growth processes more strongly than the photosynthetic mechanism, which responds to stress by increasing the allocation of photosynthates to secondary metabolite synthesis (Seigler, 1998).

In the past, culture practices developed for anthocyanin production proved unstable over the long term, and these production systems remain largely noncommercial. A more reliable system for enhanced anthocyanin production is of considerable value for large-scale production that relies on stability in color determination (Zhang et al., 2014).

Supplemental lighting has been used to change leaf coloration and increase ornamental value of succulent plants. Metal halide and high-pressure sodium lamps changed the leaf color of Crassula ovata ('Hummel's Sunset' and 'Gollum' varieties) (Park et al., 2015). The most desirable leaf color, red, was obtained under metal halide lamps. Highpressure sodium lamps resulted in desirable ornamental traits in C. ovata 'Gollum': compact with leaves and branches.

Anthocyanin accumulation in sugar cane (Saccharum officinarum) increases when day/night temperatures are increased from $28 / 23{ }^{\circ} \mathrm{C}$ to $40 / 35^{\circ} \mathrm{C}$ (Wahid, 2007). Glucose promotes anthocyanin biosynthesis in apple (Hu et al., 2016). Deficiencies in nitrogen and phosphate directly influence the accumulation of phenylpropanoids. Potassium, sulfur, and magnesium deficiencies reportedly increase phenolic concentrations (Dixon and Paiva, 1995). Nanoparticles of titanium dioxide $\left(\mathrm{TiO}_{2}\right)$ have a decolorizing effect (Shah, 2013).

Nanotechnology is an interdisciplinary science with a wide range of applications in major sectors of agriculture, including the enhancement of production (Aslani et al., 2014). The chemical product Aromatic Garden
(Ag) used in our experiments was manufactured by the Nippon Earth Chemical Co., Ltd. (Tokyo, Japan). Its main active ingredient is $\mathrm{TiO}_{2}$, which occurs in nanoparticle form (Kumar et al., 2014). The chemical product Sowing Goodliness $(\mathrm{Sg})$ was purchased from Sowing Goodliness Flower, Qingdao, China. $\mathrm{Sg}$ contains multiple nutrients, including potassium, nitrogen, magnesium, and phosphorus. Its main component is potassium fertilizer. The contents of the nutrients in $\mathrm{Sg}$ are listed by the manufacturer as $\mathrm{K}^{+} \approx 40.5 \mathrm{~g} /$ $\mathrm{L}, \mathrm{N}^{5+} \approx 20.1 \mathrm{~g} / \mathrm{L}, \mathrm{P}^{3+} \approx 12.2 \mathrm{~g} / \mathrm{L}, \mathrm{S}^{2+} \approx 3.5$ $\mathrm{g} / \mathrm{L}, \mathrm{Mg}^{2+} \approx 1.8 \mathrm{~g} / \mathrm{L}, \mathrm{Ca}^{2+} \approx 1.6 \mathrm{~g} / \mathrm{L}$, and other micronutrients $\approx 0.5 \mathrm{~g} / \mathrm{L}$.

We investigated the effects of $\mathrm{Ag}$ and $\mathrm{Sg}$ on the growth and ornamental value of $S$. rubrotinctum. Changes in chlorophyll content, carotenoid content, anthocyanin content, chromaticity, and growth parameters were determined quantitatively. We aimed to 1) broaden the range of available procedures to improve the ornamental value of succulents during commercial production, and 2) improve understanding of anthocyanin production. Our goal is to develop a rapid process to change foliar coloration in succulents. The information we provide will expand the understanding of chlorophyll degradation.

\section{Materials and Methods}

Experimental design. Two-year-old $S$. rubrotinctum plants propagated from leaf cuttings and with stable growth status were supplied by the Yixinyi Horticultural Plants Company (Changsha, China). The plants were removed from the soil in which they

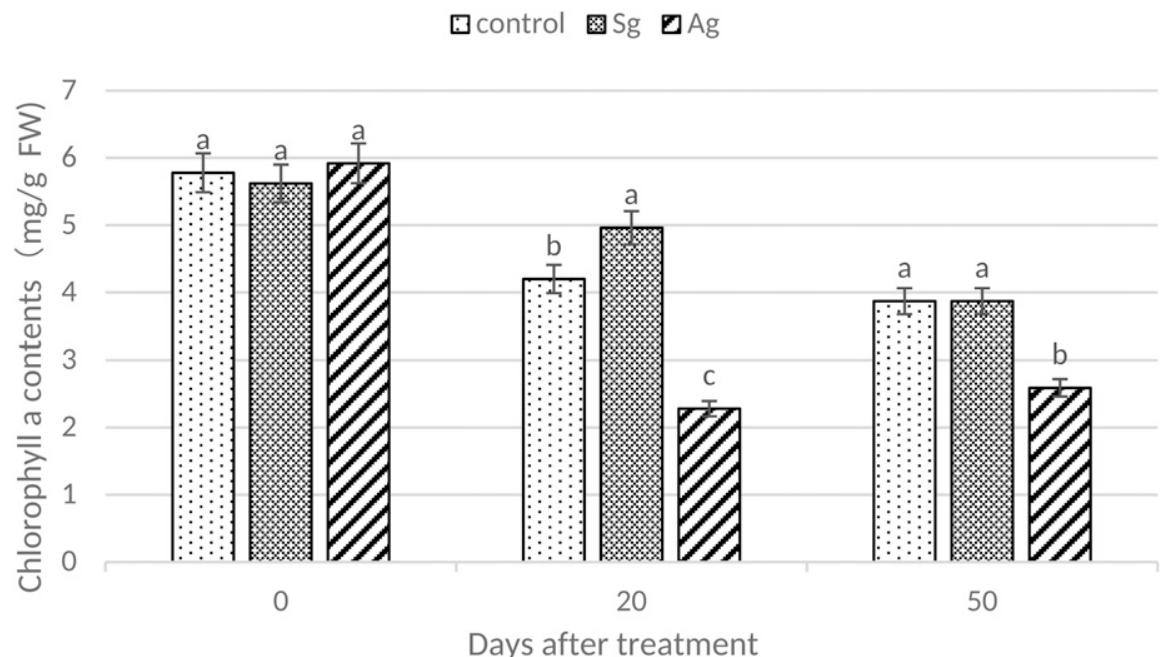

Fig. 1. Changes in the chlorophyll a contents of Sedum rubrotinctum leaves subjected to Sowing Goodliness $(\mathrm{Sg})\left(\mathrm{K}^{+} \approx 40.5 \mathrm{~g} / \mathrm{L}, \mathrm{N}^{5+} \approx 20.1 \mathrm{~g} / \mathrm{L}, \mathrm{P}^{3+} \approx 12.2 \mathrm{~g} / \mathrm{L}, \mathrm{S}^{2+} \approx 3.5 \mathrm{~g} / \mathrm{L}, \mathrm{Mg}^{2+} \approx 1.8 \mathrm{~g} / \mathrm{L}, \mathrm{Ca}^{2+} \approx\right.$ $1.6 \mathrm{~g} / \mathrm{L}$, other micronutrients $\approx 0.5 \mathrm{~g} / \mathrm{L}$ ) and Aromatic Garden $(\mathrm{Ag})$ (main active ingredient: titanium dioxide) treatments. Values are means \pm SD $(n=3)$. Different lower case letters identify significant pairwise differences in means within time intervals (least significant difference test; $P<0.05$ ). $\mathrm{FW}=$ fresh weight.

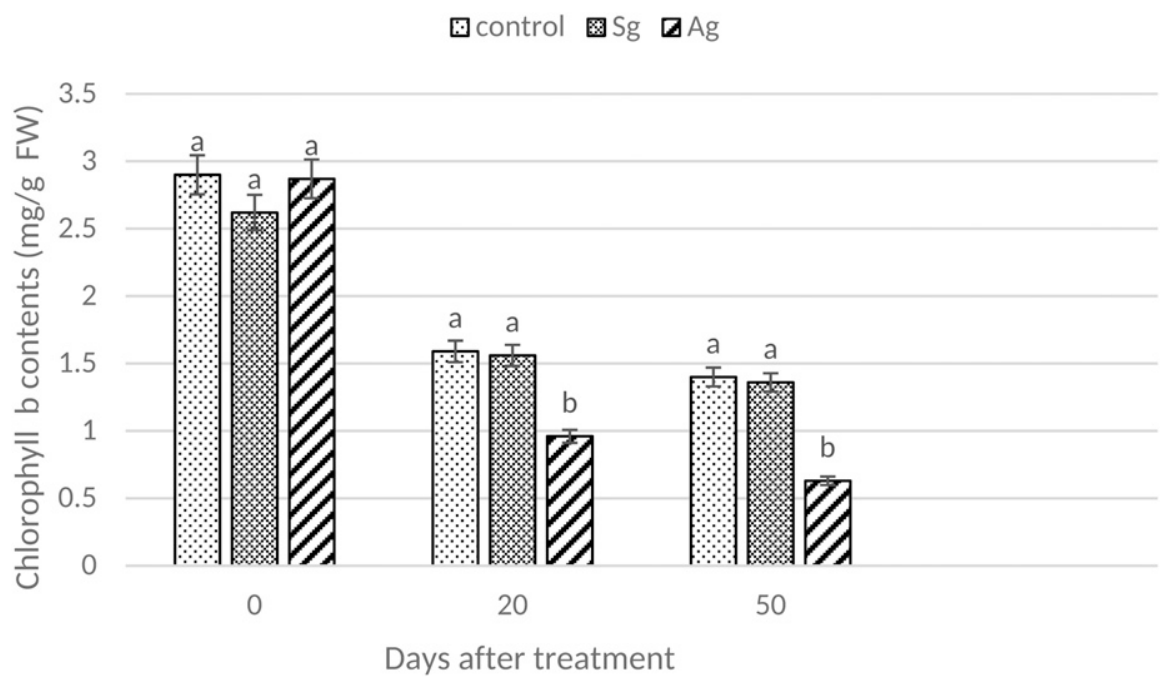

Fig. 2. Changes in the chlorophyll b contents of Sedum rubrotinctum leaves subjected to Sowing Goodliness ( $\mathrm{Sg})$ and Aromatic Garden $(\mathrm{Ag})$ treatments. Values are means $\pm \mathrm{SD}(\mathrm{n}=3)$. Different lower case letters identify significant pairwise differences in means within time intervals (least significant difference test; $P<0.05)$. FW = fresh weight. 
were purchased. After $1 \mathrm{~d}$, they were planted in pots $(7.0 \times 7.0 \times 7.5 \mathrm{~cm})$ containing a blended substrate of peat, slag, and vermiculite at $2: 1: 1$ by volume.

Three weeks later, the experiment was initiated using a completely randomized design. In the Ag treatment, $5 \mathrm{~g}$ of $\mathrm{Ag}$ per pot was spread each month on the soil containing a single plant; this procedure enabled root absorption of the product. $\mathrm{Ag}$ treatment was applied monthly. For the $\mathrm{Sg}$ treatment, $10 \mathrm{~mL}$ of $\mathrm{Sg}$ solution $(\mathrm{Sg} /$ water at 1:50 by volume) was sprayed on the leaves of each plant every $4 \mathrm{~d}$. In the control treatment, $10 \mathrm{~mL}$ water was sprayed on the leaves of each plant every $4 \mathrm{~d}$. Ten plants per treatment were arranged outdoors in a completely randomized design. The experiment was conducted during the period of April through October, during which temperatures ranged from 26 to $38^{\circ} \mathrm{C}$. Leaf samples were collected for analysis on 0,20 , and $50 \mathrm{~d}$ after trial initiation.

Estimation of chlorophyll, carotenoid, and anthocyanin contents and chromaticity. Chromaticity was determined before and after the experiment using the Royal Horticultural Society Color Chart.

Chlorophyll and carotenoid contents were determined by spectrophotometry following the procedures of Lichtenthaler and Wellburn (1983). We extracted leaves collected from the same within-plant locations of treated and control specimens. We transferred a $0.2-\mathrm{g}$ sample to a vessel containing $10 \mathrm{~mL}$ acetone, and kept it in the dark for $36 \mathrm{~h}$ until all chlorophyll and carotenoid were dissolved in the extract solution and all leaves had turned white. The light absorbance of the extract was determined using a spectrophotometer at 663, 646, and $470 \mathrm{~nm}$. Chlorophyll and carotenoid contents were calculated using the following equations (total chlorophyll is the sum of chlorophyll a and chlorophyll b concentrations):

$$
\begin{aligned}
& \mathrm{Ca}=12.21 \mathrm{OD}_{663}-2.81 \mathrm{OD}_{646} \\
& \mathrm{Cb}=20.13 \mathrm{OD}_{646}-5.03 \mathrm{OD}_{663}
\end{aligned}
$$$$
\mathrm{Cx} . \mathrm{c}=\left(1000 \mathrm{OD}_{470}-3.27 \mathrm{Ca}-104 \mathrm{Cb}\right) / 229
$$

where $\mathrm{Ca}$ and $\mathrm{Cb}$ are the concentrations of chlorophyll a and chlorophyll b, respectively; $\mathrm{Cx} \cdot \mathrm{c}$ is the total concentration of carotenoids; and $\mathrm{OD}_{663}, \mathrm{OD}_{646}$, and $\mathrm{OD}_{470}$ are the chloroplast pigment optical densities at wavelengths of 663,646 , and $470 \mathrm{~nm}$, respectively

Anthocyanin contents were determined using a Shimadzu ultraviolet-2450 ultravioletvisible light spectrophotometer (Wang et al., 2008). We immersed $0.1 \mathrm{~g}$ of sampled leaves in $10 \mathrm{~mL}$ of solvent mix $\left(1.5 \mathrm{~mol} \cdot \mathrm{L}^{-1}\right.$ muriatic acid in $95 \%$ ethanol) and kept them in the dark. After $24 \mathrm{~h}$, the absorbance at $535 \mathrm{~nm}$ of triplicate 1$\mathrm{mL}$ samples of extract was determined using a spectrometer. Deionized water was used as a control. Anthocyanin contents were calculated following the procedure of $\mathrm{Hu}$ (Hu et al., 2004).
Measurement of growth parameters. Lateral buds and leaf numbers were counted $50 \mathrm{~d}$ and 5 months after initiating the experiment. Leaf length, leaf thickness, and plant canopy diameters were measured with an electronic Vernier caliper (GuangLu, Guilin, China). Plant height was measured with a steel measuring tape.

Statistical analysis. Data are presented as the mean \pm SD $(n=3)$. One-way analysis of variance was used to test for significant effects of nanoparticles and nutrients on the contents of chlorophyll, carotenoids, and anthocyanin. Least significant difference multiple comparisons tests (LSD-tests) were used to identify significant pairwise differences between means. The significance level was set at $P<0.05$ for all tests.

\section{Results}

Chlorophyll content. Exposure of plants to $\mathrm{Sg}$ and $\mathrm{Ag}$ treatments resulted in reductions in the chlorophyll a contents (Fig. 1). On day 0, chlorophyll a content did not differ between $\mathrm{Ag}$ and $\mathrm{Sg}$ treatments (Fig. 1); however, means were significantly different on days 20 and 50 . On day 20, the chlorophyll a content in the Agtreated plants fell to $61.49 \%$. Declines in response to the $\mathrm{Sg}$ and control treatments were less steep; the chlorophyll a content dropped by $11.74 \%$ with $\mathrm{Sg}$ treatment and by $27.34 \%$ in the control. On day 50, chlorophyll a content remained lowest in the Ag-treated plants. The Sg-treated and control plants did not differ significantly. Chlorophyll a content was similar between days 20 and 50 for all treatments.

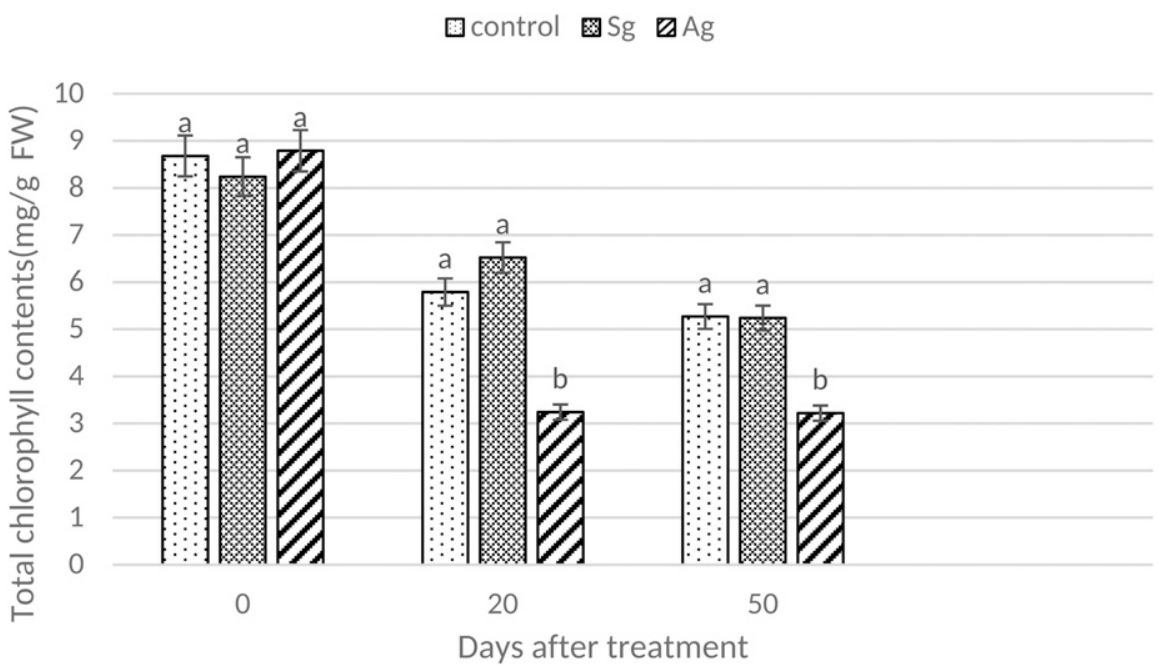

Fig. 3. Changes in total chlorophyll contents of Sedum rubrotinctum leaves subjected to Sowing Goodliness $(\mathrm{Sg})$ and Aromatic Garden $(\mathrm{Ag})$ treatments. Values are means \pm SD $(\mathrm{n}=3)$. Different lower case letters identify significant pairwise differences in means within time intervals (least significant difference test; $P<0.05)$. $\mathrm{FW}=$ fresh weight.

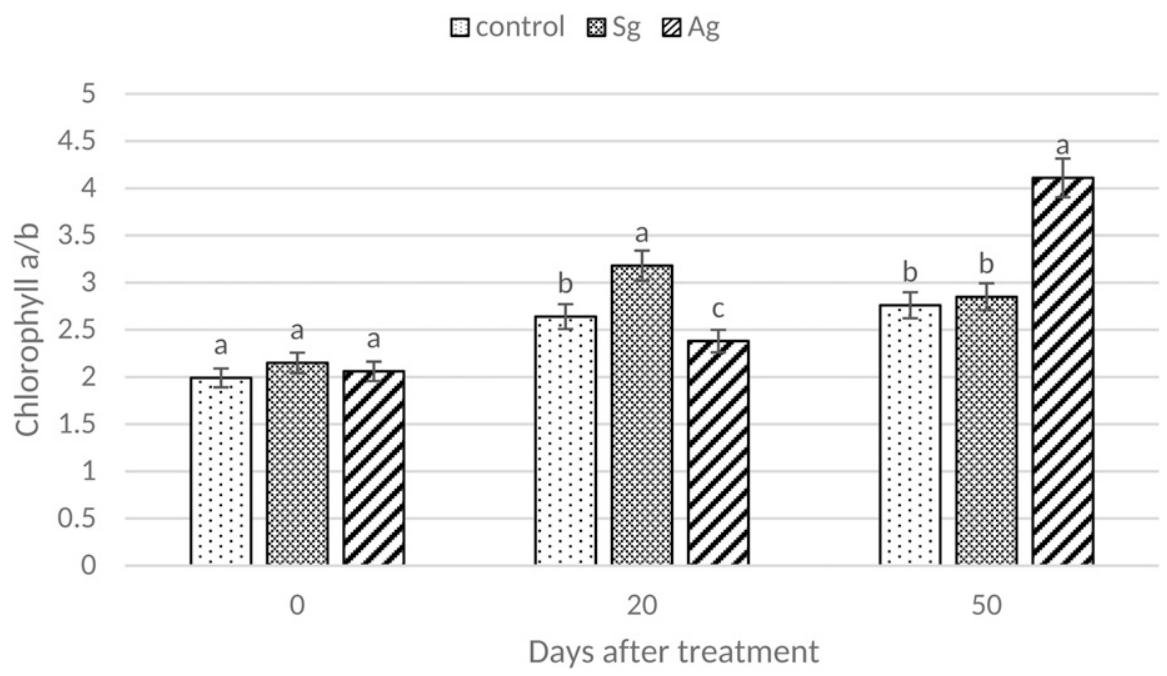

Fig. 4. Changes in the chlorophyll a/b ratio in Sedum rubrotinctum leaves subjected to Sowing Goodliness $(\mathrm{Sg})$ and Aromatic Garden $(\mathrm{Ag})$ treatments. Values are means $\pm \mathrm{SD}(\mathrm{n}=3)$. Different lower case letters identify significant pairwise differences in means within time intervals (least significant difference test; $P<0.05)$. 


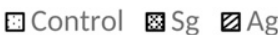

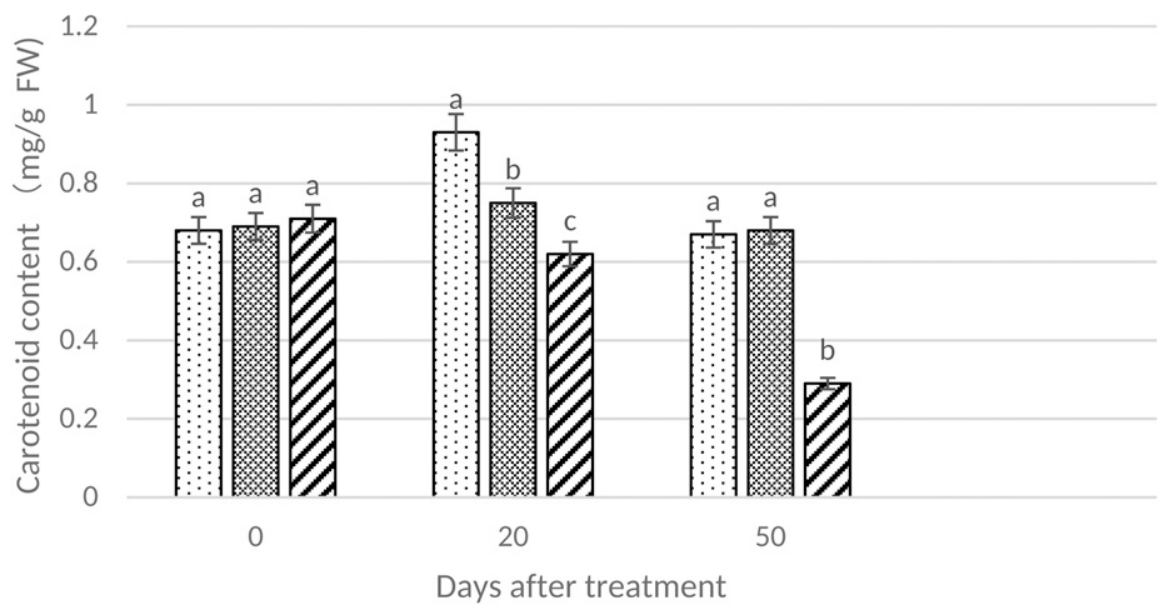

Fig. 5. Changes in the carotenoid content in Sedum rubrotinctum leaves subjected to Sowing Goodliness $(\mathrm{Sg})$ and Aromatic Garden $(\mathrm{Ag})$ treatments. Values are means $\pm \mathrm{SD}(\mathrm{n}=3)$. Different lower case letters identify significant pairwise differences in means within time intervals (least significant difference test; $P<0.05) . \mathrm{FW}=$ fresh weight.

\section{$\square$ Control $\otimes \mathrm{Sg}$ 囚Ag}

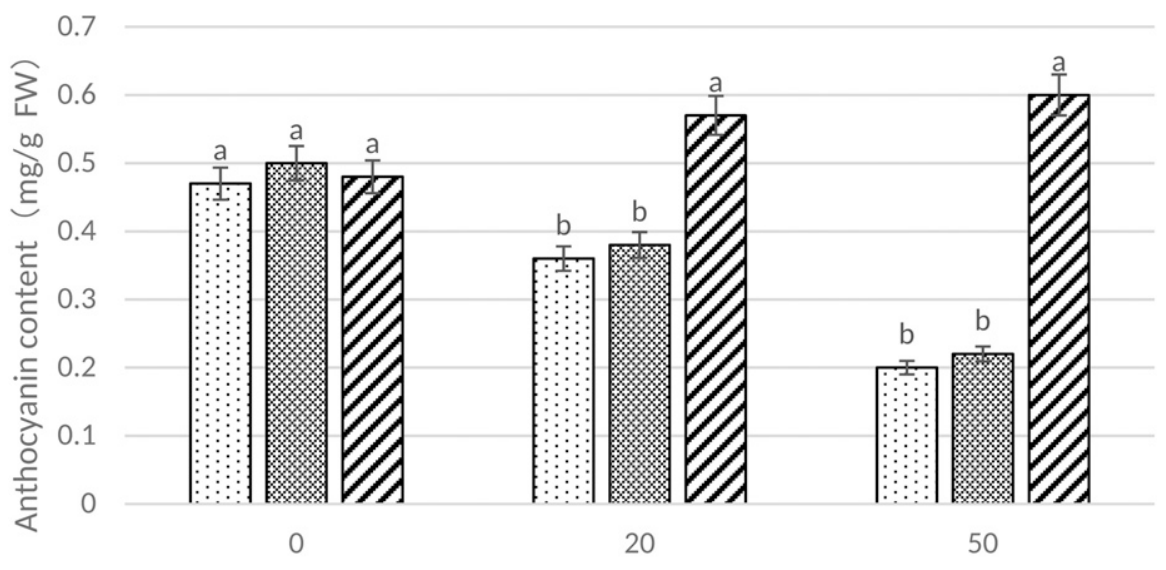

Days after treatment

Fig. 6. Changes in the anthocyanin contents of Sedum rubrotinctum leaves subjected to Sowing Goodliness $(\mathrm{Sg})$ and Aromatic Garden $(\mathrm{Ag})$ treatments. Values are means $\pm \mathrm{sD}(\mathrm{n}=3)$. Different lower case letters identify significant pairwise differences in means within time intervals (least significant difference test; $P<0.05) . \mathrm{FW}=$ fresh weight.
Chlorophyll b contents were also influenced by the $\mathrm{Ag}$ and $\mathrm{Sg}$ treatments (Fig. 2). It dropped faster than chlorophyll a during the duration of the trial. Declines after 20 and $50 \mathrm{~d}$ were most rapid in response to the $\mathrm{Ag}$ treatment. Chlorophyll b values differed significantly between the Ag-treated and control plants. Trends were similar between the $\mathrm{Sg}$ and $\mathrm{Ag}$ treatments, and $\mathrm{Sg}$ treatment means were not significantly different from the control. Increasing temperatures during the spring may explain the declining chlorophyll $\mathrm{b}$ content. The large declines in chlorophyll b content in the Ag treatment may have resulted from the interactive effect of $\mathrm{Ag}$ and increasing temperature.

The $\mathrm{Ag}$ and $\mathrm{Sg}$ treatments also reduced total chlorophyll content (Fig. 3). The maximum decline after $20 \mathrm{~d}$ occurred in the $\mathrm{Ag}$ treated plants $(63.14 \%$ decline $)$. The $\mathrm{Sg}$ treatment reduced the total chlorophyll contents by $20.87 \%$ after $20 \mathrm{~d}$. Total chlorophyll contents were broadly similar between days 20 and 50 for all treatments.

The chlorophyll $\mathrm{a} / \mathrm{b}$ ratio increased over time in all treatments (Fig. 4). After $20 \mathrm{~d}$, the ratio was significantly higher in the $\mathrm{Sg}$-treated plants. Between days 0 and 20, the ratio in the Ag-treated plants increased by only $15.53 \%$. On day 50, the elevated ratio value in the $\mathrm{Ag}$ treated plants was significantly higher than values in the Sg-treated and control plants.

Carotenoid content. Carotenoid content was also affected by the $\mathrm{Ag}$ and $\mathrm{Sg}$ treatments (Fig. 5). Between days 0 and 20, the values in the Sg-treated and control plants increased by $8.70 \%$ and $36.67 \%$, respectively; values had dropped somewhat by day 50 (by $9.33 \%$ and $27.96 \%$ in the Sg-treated and control plants, respectively). Carotenoid content in the Agtreated plants decreased by $12.68 \%$ between days 0 and 20 , and by $53.23 \%$ by day 50 . The sharp declines with Ag treatment may have resulted from nanoparticle stress that induced photodamage.

Anthocyanin content. The $\mathrm{Sg}$ treatment reduced anthocyanin content in the plants over the course of the experiment, whereas $\mathrm{Ag}$ treatment increased the content (Fig. 6). The highest anthocyanin content occurred in the Ag-treated plants on day 50. On day 20, the anthocyanin content with $\mathrm{Ag}$ treatment was 1.5 -fold higher than with $\mathrm{Sg}$ treatment.
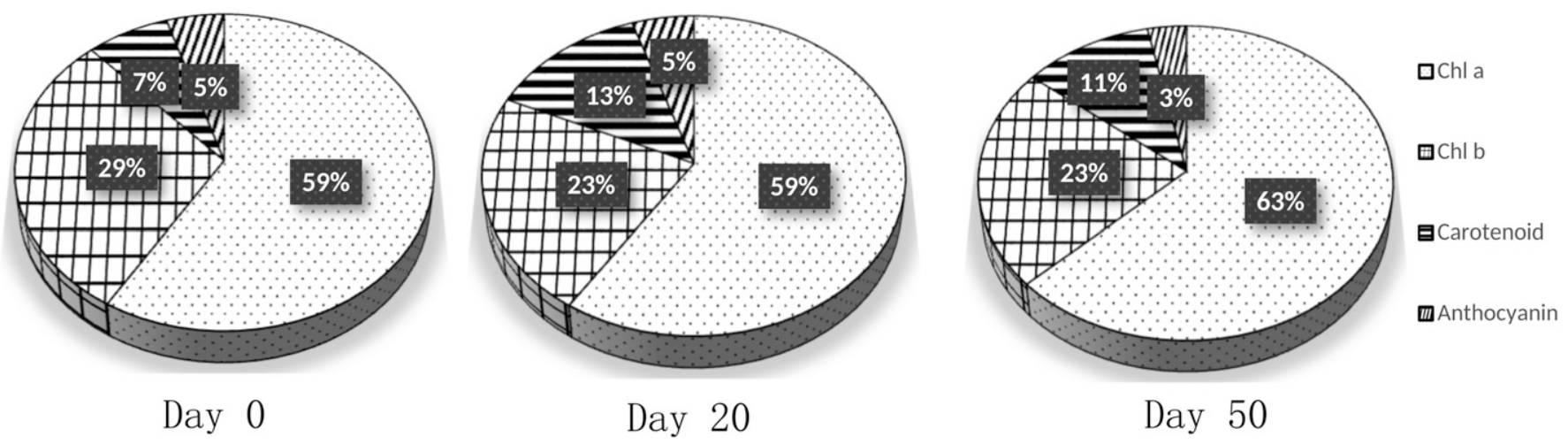

Fig. 7. Pigment proportions in control plants. $\mathrm{Chl}=$ chlorophyll. 
On day 50, the content in the Ag-treated plants was 2.73-fold higher and differed significantly from values in the plants receiving the other two treatments.
Relative proportions of pigments. The relative proportions of pigment produced in response to the three treatments on days 0,20 , and 50 are shown in Figs. 7-9. The relative proportion of the carotenoids increased slightly over time, but the relative proportions of the other pigments did not (Fig. 7).

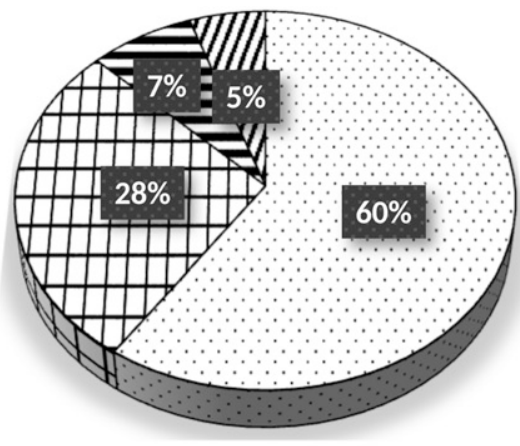

Day 0

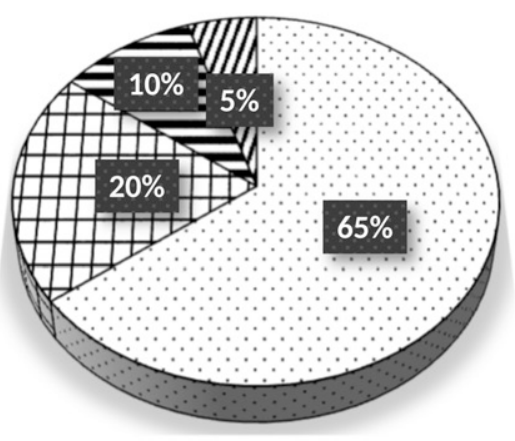

Day 20

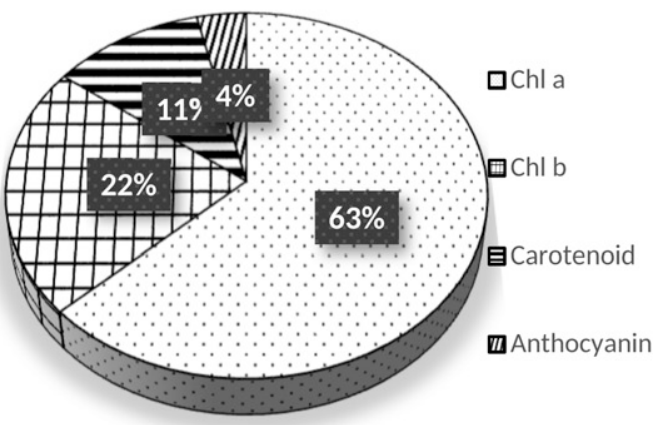

Day 50

Fig. 8. Pigment proportions in Sowing Goodliness $(\mathrm{Sg})$-treated plants. $\mathrm{Chl}=$ chlorophyll .

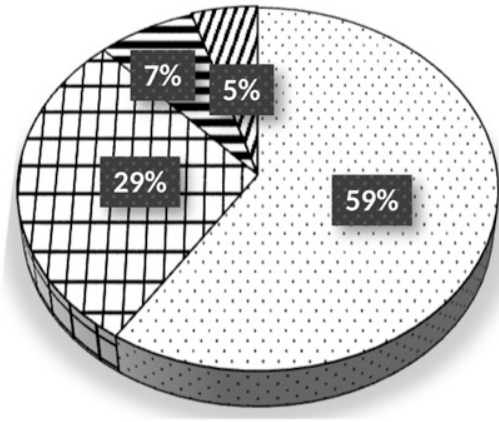

Day 0

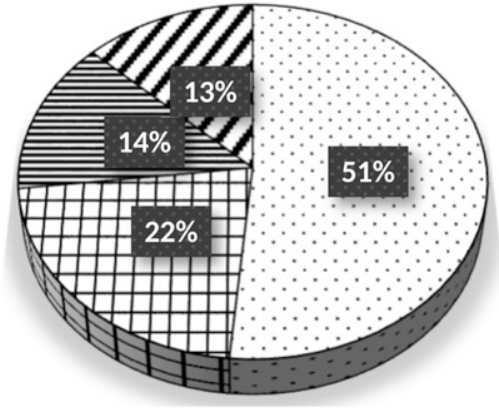

Day 20

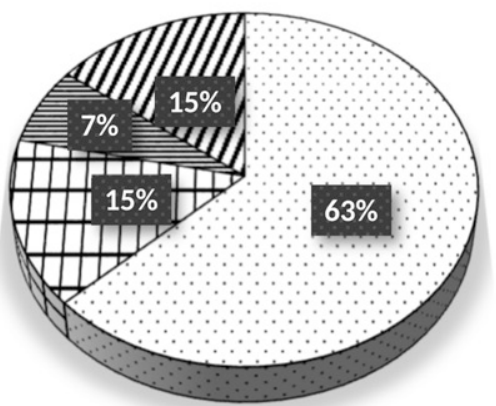

Day 50 $\square \mathrm{Chl}$ a

巴Chl b

目Carotenoid

四Anthocyanin

Fig. 9. Pigment proportions in Aromatic Garden (Ag)-treated plants. $\mathrm{Chl}=$ chlorophyll.

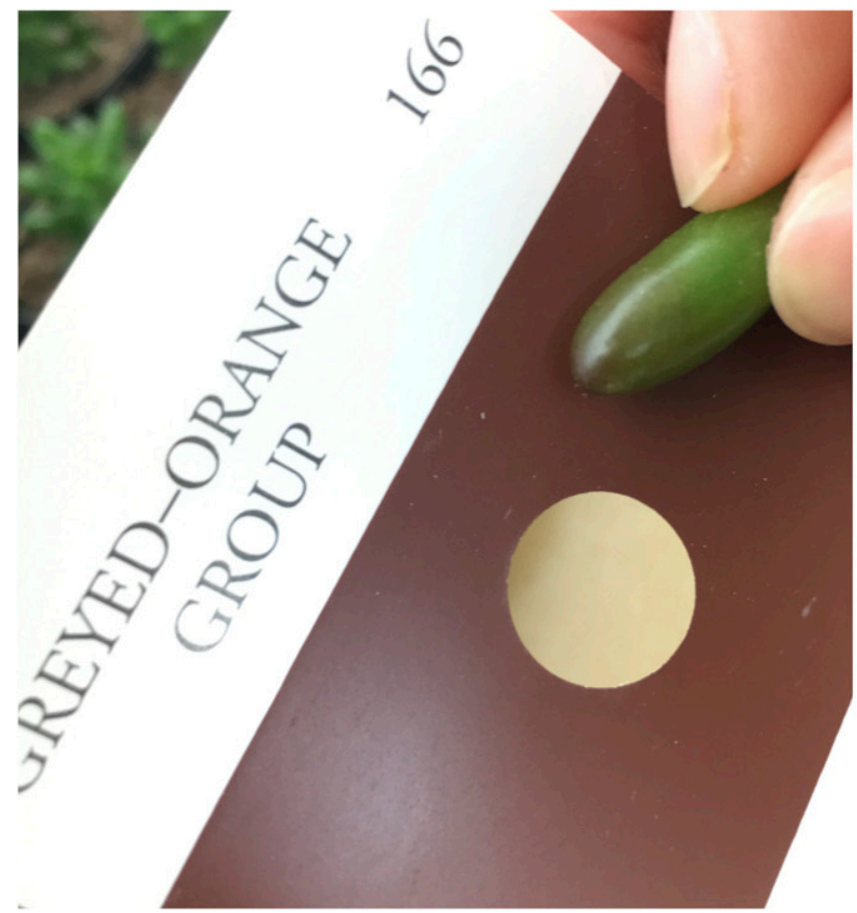

\section{GREEN

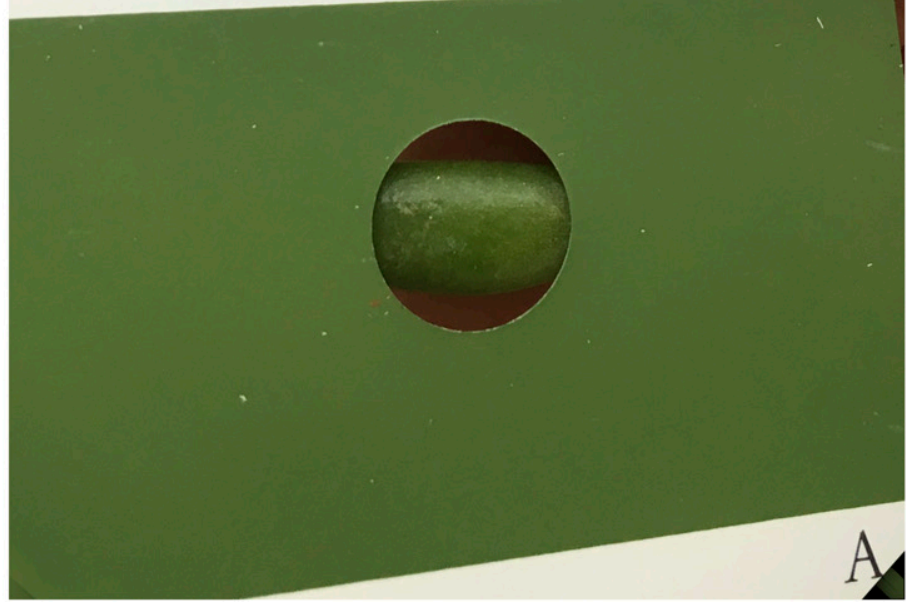

Fig. 10. Leaf chromaticity before treatment. (A) Leaf apices. (B) Remaining leaf portions. 
Sg treatment increased the relative proportions of chlorophyll a and the carotenoids, but not the relative proportion of anthocyanin (Fig. 8).

The Ag treatment considerably reduced the relative proportion of chlorophyll $b$, and significantly increased the relative proportion of anthocyanin. This treatment increased the relative proportion of carotenoids on day 20 , but the relative proportion had returned to its original value by day 50 (Fig. 9).

Chromaticity. Leaf colors in S. rubrotinctum were affected by both the $\mathrm{Ag}$ and $\mathrm{Sg}$ treatments. Before treatment, leaf colors were unevenly distributed. The leaf apices were grayed-orange (chromaticity index 166), and the remaining leaf portions were green (chromaticity index 138) (Figs. 10 and 11).

By day 20, plants subjected to the $\mathrm{Ag}$ treatment had started to turn red, whereas plants subjected to the $\mathrm{Sg}$ treatment had become greener and the leaves were more densely packed on the stems (Fig. 12).

By day 40, Ag-treated plants had changed to a red-purple color. Some of the lower epidermis in leaves subjected to this treatment had broken and roughened, thereby reducing luster (Fig. 13). The leaf apices of plants exposed to the $\mathrm{Sg}$ treatment were slightly red. Leaf colors did not change significantly over time in the control.

On day 50, plants in the $\mathrm{Sg}$ and control treatments were still green (chromaticity in- dices: green group 138-A to green group 137 A; Figs. 11 and 14 and Table 1). The chromaticity indices of the Ag-treated plants shifted from green group 138-A to red-purple group 64-A (Table 1). A few Ag-treated plants exhibited attractive colors, good shape, and healthy growth status, but most were no longer upright, lacked luster, and were partially defoliated, especially in the lower sections (Figs. 15 and 16).

Growth of S. rubrotinctum. We collected plant growth data on day 50 . The Ag treatment had significant negative effects (Table 2). It reduced lateral bud numbers by $50 \%$ below numbers in the control plants. Leaf numbers were also much lower than in the other two treatments, perhaps because of slow growth
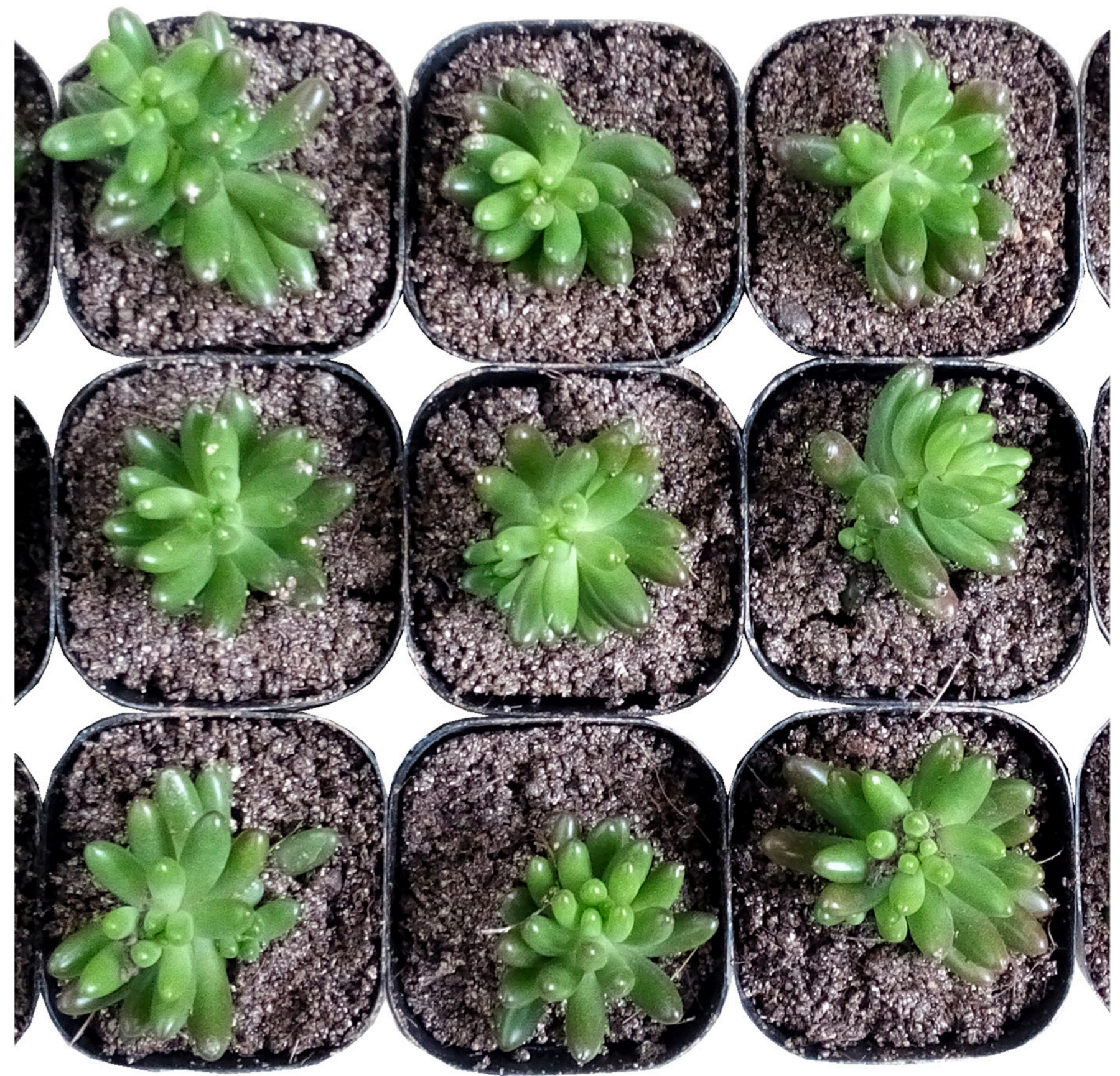

Fig. 11. Plant appearance before treatment. 

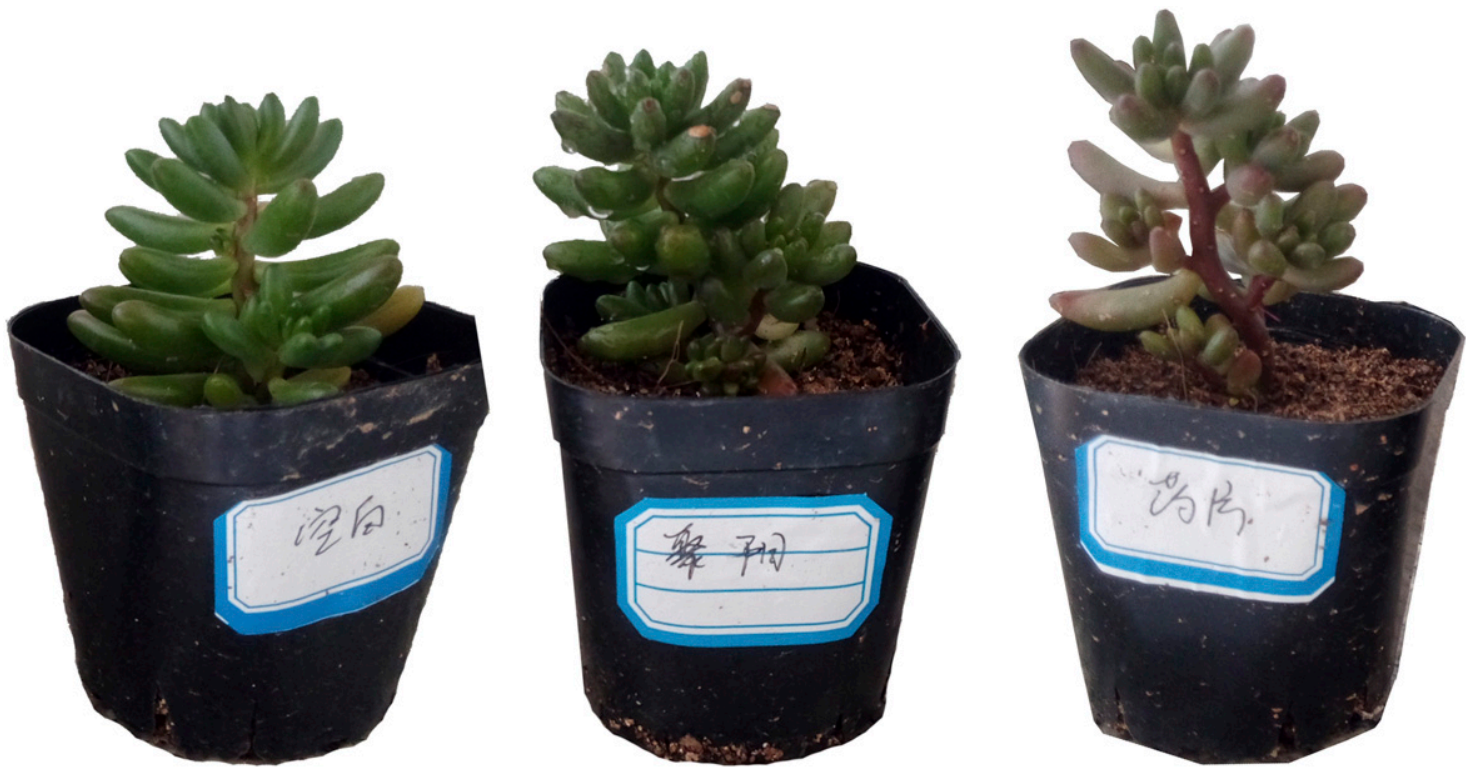

Fig. 12. Appearance of control, Sowing Goodliness (Sg)-treated, and Aromatic Garden (Ag)-treated plants on day 20.
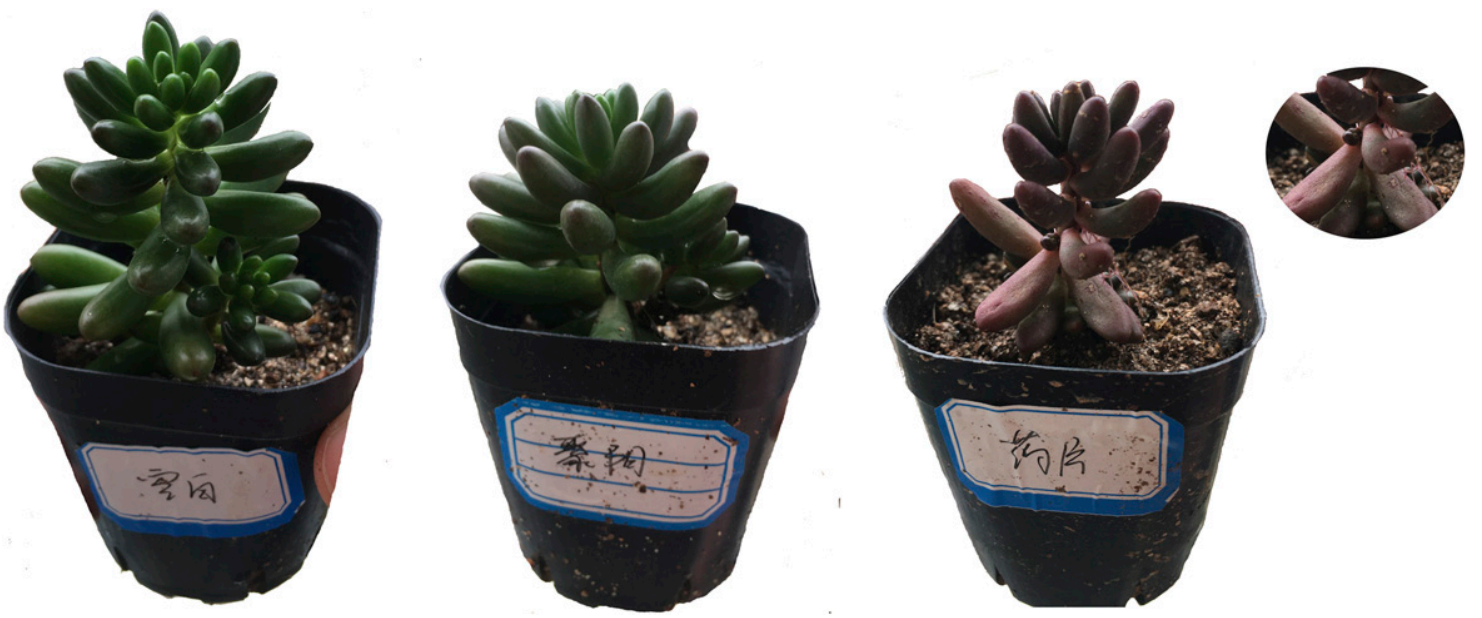

Fig. 13. Appearance of control, Sowing Goodliness (Sg)-treated, and Aromatic Garden (Ag)-treated plants on day 40. Inset: magnified detail of Ag-treated plants.
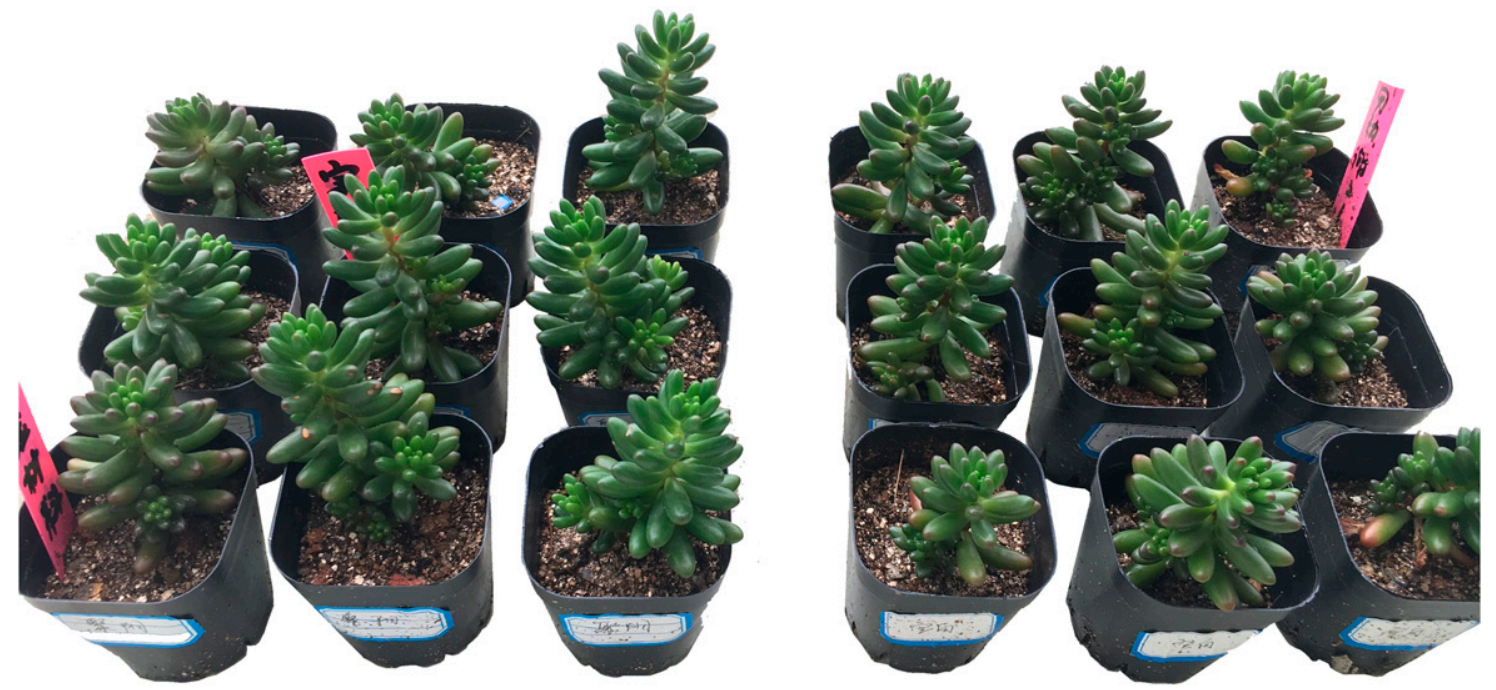

Fig. 14. Appearance of Sowing Goodliness (Sg)-treated and control plants on day 50. 
and defoliation. Leaf lengths and thicknesses were significantly lower in the Ag-treated plants, as were canopy diameter and plant height. Canopy diameters and plant heights were significantly greater with the Sg treatment.

The Ag treatment induced a desirable plant color, but at the cost of plant growth. However, we examined the specimens again after 5 months ( 2 months after the trial was ended) and found that plants that had been subjected to the Ag treatment were very attractive, with healthy leaves arrayed appropriately on the stems (Fig.
17). Control plants appeared rather thin, with some overgrowth, and were somewhat lopsided. Sg-treated plants had abundant lateral branches and had grown well over the period since the last measurements were made. Red aerial adventitious roots grew from the branches. Whole Sg-treated plants had lost ornamental value by the fifth month. The leaf color in all three treatments was in the chromaticity index green group 137-A.

Growth parameters after 5 months are listed in Table 3. Survival was reduced by the Ag treatment. All Sg-treated plants sur-

Table 1. Chromaticity indices on days 0 and 50 .

\begin{tabular}{lll}
\hline Treatment & Day 0 & Day 50 \\
\hline Control & Green group 138-A & Green group 137-A \\
$\mathrm{Sg}$ & Green group 138-A & Green group 137-A \\
$\mathrm{Ag}$ & Green group 138-A & Red-purple group 64-A \\
\hline
\end{tabular}

$\mathrm{Ag}=$ Aromatic Garden; $\mathrm{Sg}=$ Sowing Goodliness . Red-purple group 64-A

$\mathrm{Sg}$, treated with $\mathrm{K}^{+} \approx 40.5 \mathrm{~g} / \mathrm{L}, \mathrm{N}^{5+} \approx 20.1 \mathrm{~g} / \mathrm{L}, \mathrm{P}^{3+} \approx 12.2 \mathrm{~g} / \mathrm{L}, \mathrm{S}^{2+} \approx 3.5 \mathrm{~g} / \mathrm{L}_{,} \mathrm{Mg}^{2+} \approx 1.8 \mathrm{~g} / \mathrm{L}, \mathrm{Ca}^{2+} \approx 1.6 \mathrm{~g} / \mathrm{L}$ other micronutrients $\approx 0.5 \mathrm{~g} / \mathrm{L} ; \mathrm{Ag}$, treated with titanium dioxide.

vived and were growing well. All plants that survived the $\mathrm{Ag}$ treatment had begun to regrow, but still exhibited the lowest lateral bud numbers, leaf numbers, leaf lengths, leaf thicknesses, canopy diameters, and heights. Leaves were most abundant under Sg treatment because all of the lateral buds grew and produced many leaves.

\section{Discussion}

The two chemical products tested in this study had different formulations that were responsible for differences in plant morphologies. Sg contains plant fertilizers, with potassium as its main ingredient. Potassium reportedly induces the accumulation of phenolic compounds, but its effect on foliar color change was limited in our experiment. $\mathrm{Sg}$ provided many nutrients and had a positive effect on plant growth: Sg-treated plants grew much faster than Ag-treated or control plants. Sg induction of lateral buds and leaves has potential commercial value.
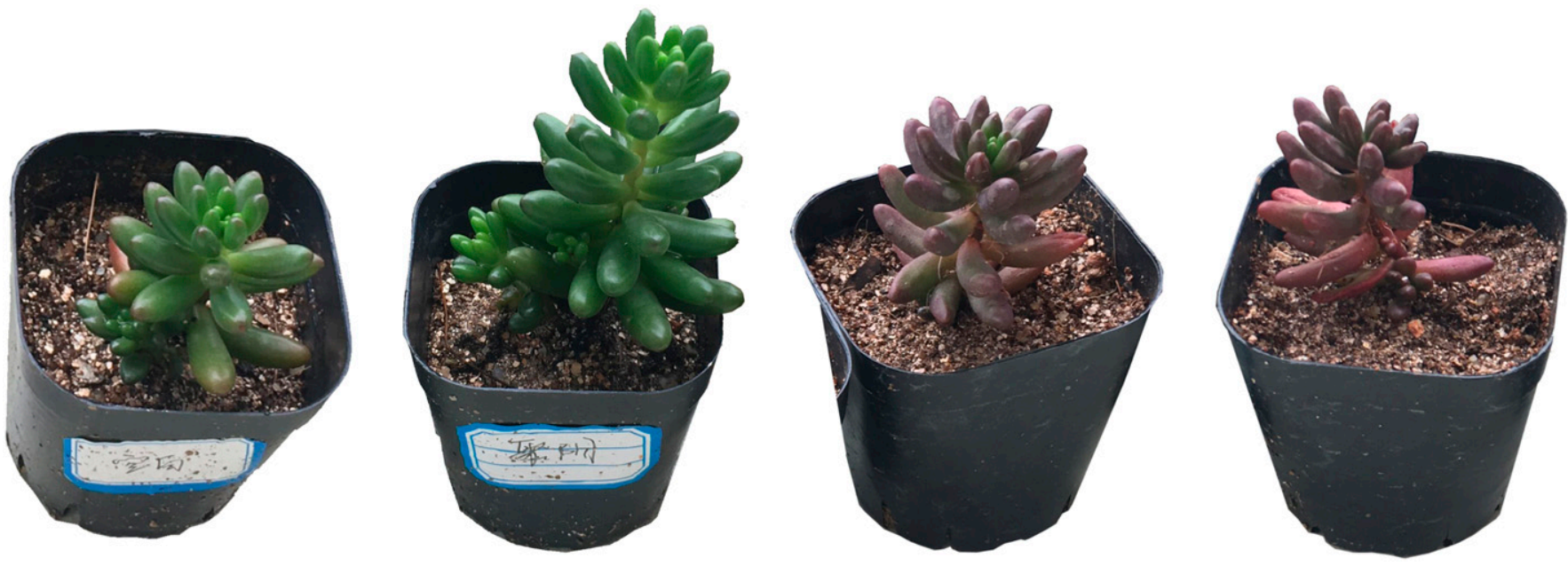

Fig. 15. Appearance of control, Sowing Goodliness (Sg)-treated, and Aromatic Garden (Ag)-treated plants on day 50.
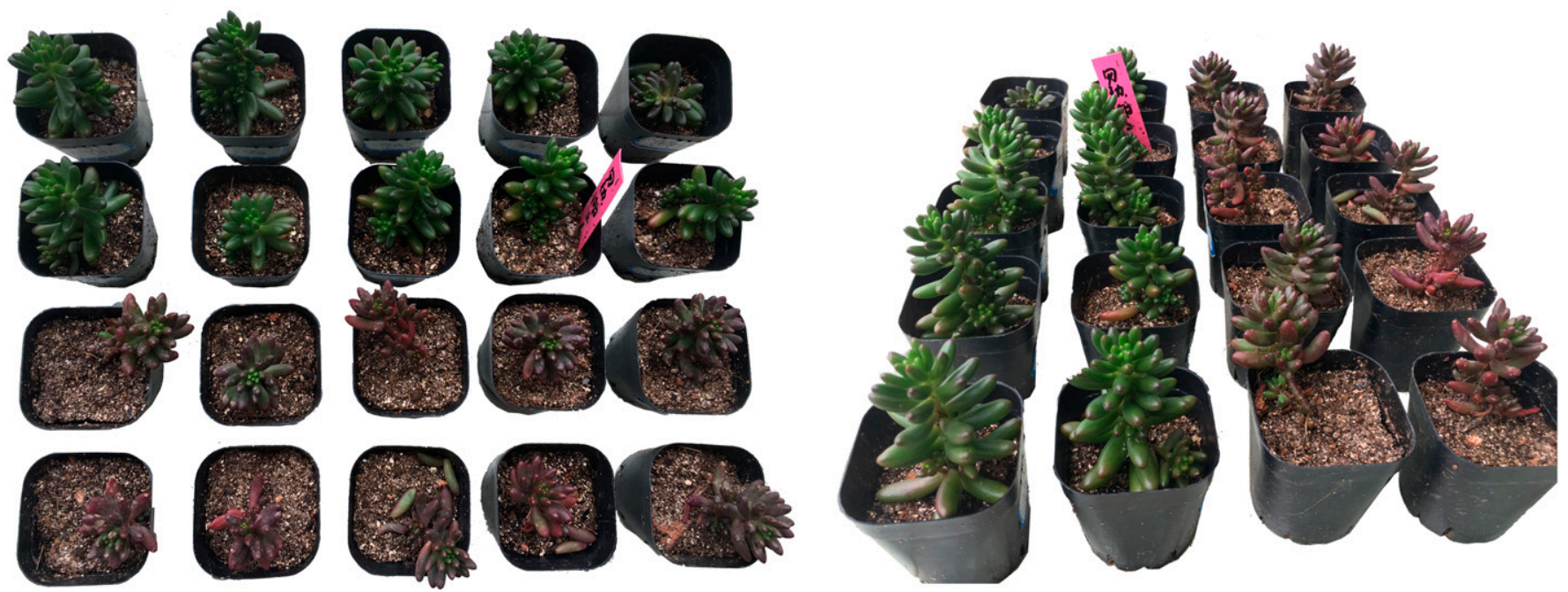

Fig. 16. Appearance of Aromatic Garden (Ag)-treated and control plants on day 50. 
Table 2. Growth parameters under three treatments on day 50 .

\begin{tabular}{|c|c|c|c|c|c|c|}
\hline Treatment & Lateral bud no. & Leaf no. & Leaf length $(\mathrm{mm})$ & Leaf thickness (mm) & Canopy diam (mm) & $\mathrm{Ht}(\mathrm{cm})$ \\
\hline Control & $4.00 \pm 0.33 \mathrm{a}$ & $48.00 \pm 1.76 \mathrm{a}$ & $19.72 \pm 0.71 \mathrm{a}$ & $5.55 \pm 0.18 \mathrm{a}$ & $54.42 \pm 0.37 \mathrm{~b}$ & $6.60 \pm 0.26 \mathrm{~b}$ \\
\hline $\mathrm{Ag}$ & $2.00 \pm 0.33 \mathrm{~b}$ & $32.00 \pm 0.88 b$ & $15.35 \pm 0.73 b$ & $3.24 \pm 0.21 \mathrm{~b}$ & $40.44 \pm 0.81 \mathrm{c}$ & $4.47 \pm 0.20 \mathrm{c}$ \\
\hline
\end{tabular}

$\mathrm{Ag}=$ Aromatic Garden; $\mathrm{Sg}=$ Sowing Goodliness.

Values are means $\pm \mathrm{SD}(\mathrm{n}=3)$; different lower case letters indicate significant pairwise differences between treatments within each column $(P<0.05$; least significant difference test).

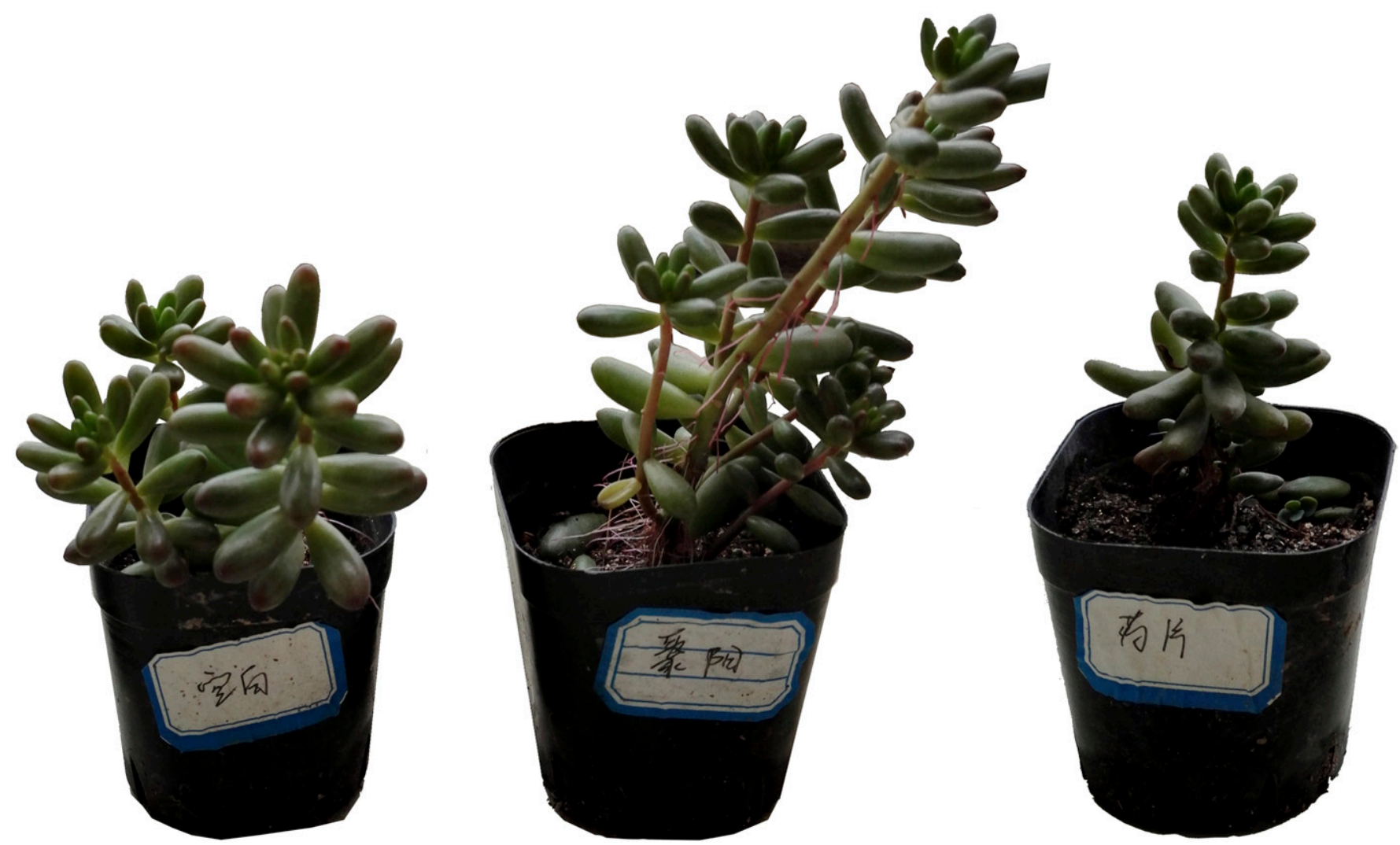

Fig. 17. Appearance of plants 5 months after the onset of treatment (and 2 months after treatments were discontinued).

Table 3. Growth parameters under three treatments at 5 months after the onset of the experiment (and 2 months after treatments were discontinued).

\begin{tabular}{|c|c|c|c|c|c|c|c|}
\hline Treatment & Lateral bud no. & Leaf no. & Leaf length $(\mathrm{mm})$ & Leaf thickness $(\mathrm{mm})$ & Canopy diam (mm) & $\mathrm{Ht}(\mathrm{cm})$ & Survival (\%) \\
\hline Control & $4.00 \pm 0.00 \mathrm{~b}$ & $59.00 \pm 2.08 \mathrm{a}$ & $19.67 \pm 0.88 \mathrm{a}$ & $6.00 \pm 0.58 \mathrm{a}$ & $55.33 \pm 0.88 \mathrm{~b}$ & $13.00 \pm 0.58 \mathrm{~b}$ & 100.00 \\
\hline $\mathrm{Ag}$ & $2.40 \pm 0.40 \mathrm{c}$ & $34.60 \pm 3.83 b$ & $16.33 \pm 0.88 \mathrm{~b}$ & $4.80 \pm 0.58 \mathrm{~b}$ & $41.00 \pm 0.58 \mathrm{c}$ & $5.75 \pm 0.85 \mathrm{c}$ & 70.00 \\
\hline
\end{tabular}

$\mathrm{Ag}=$ Aromatic Garden; $\mathrm{Sg}=$ Sowing Goodliness.

Values are means \pm SD $(\mathrm{n}=3)$; different lower case letters indicate significant pairwise differences between treatments within each column $(P<0.05$; least significant difference test).

Nanotechnology is predicted to have major, long-term effects on agriculture and food production (Agrawal and Rathore, 2014). The positive morphological effects of nanomaterials include enhanced germination and improved physiological performance (e.g., in photosynthesis and nitrogen metabolism). Nanotechnology should provide mechanisms for the controlled release of agrochemicals and site-targeted delivery of diverse macromolecules needed to improve plant disease resistance, growth, and efficient nutrient utilization.
The primary components of $\mathrm{Ag}$ are $\mathrm{TiO}_{2}$ nanoparticles that have a photocatalytic function. $\mathrm{TiO}_{2}$ has attracted considerable attention in recent years because of its high oxidative power, abundance, and chemical stability. It is now widely used in environmental cleaning and energy conversion (Cui et al., 2010; Li, 2011; McGivney et al., 2017), but is less used in commercial plant production. We used Ag in our experiment as a stressor to stimulate the production of anthocyanin. $\mathrm{TiO}_{2}$ generates reactive oxygen species. When reactive oxygen levels exceed the handling capacity of plant antioxidant systems, biomacromolecules are attacked, leading to whole plant damage. We found that Ag inhibited plant growth and influenced photosynthesis. It caused chlorophyll degradation in S. rubrotinctum. Similar results have been observed in maize $(\mathrm{Yu}, 2010)$ and wheat (Aliabadi et al., 2016).

The total chlorophyll content in S. rubrotinctum was reduced by Ag treatment. The chlorophyll b content declined more rapidly than the chlorophyll a content, likely because 
in the process of chlorophyll degradation (Fig. 18) chlorophyll b is converted to chlorophyll a under the influence of chlorophyll $b$ reductase and 7-hydroxymethyl chlorophyll a reductase; further degradation steps follow (Balazadeh, 2014).

Increases in the chlorophyll $\mathrm{a} / \mathrm{b}$ ratio over time under the $\mathrm{Ag}$ treatment indicate that

\section{CH1 b}

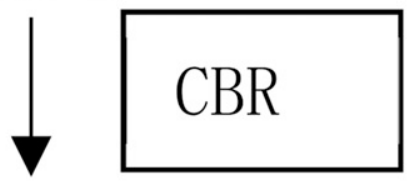

7HMCH1 a

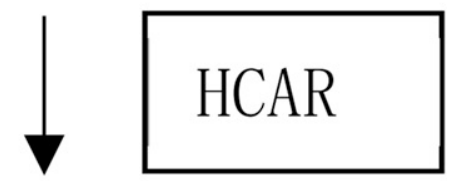

CH1 a

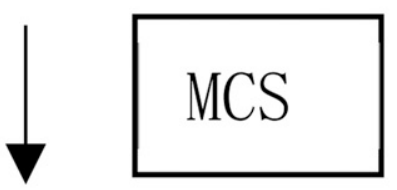

Phein a

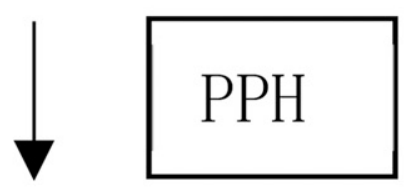

Pheide a

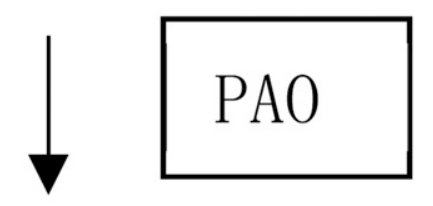

$\mathrm{RCC}$

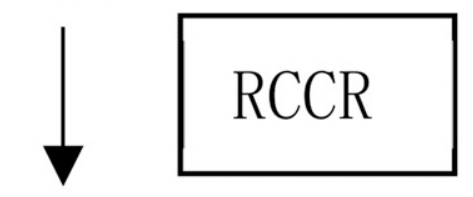

\section{PFCC}

Fig. 18. Steps in the process of chlorophyll degradation (Balazadeh, 2014). CBR $=\mathrm{Chl} \mathrm{b}$ reductase; $\mathrm{Chl} \mathrm{b}=$ Chlorophyll b; $7 \mathrm{HMChl} \mathrm{a=}$ 7-hydroxymethyl $\mathrm{Chl}$ a reductase (HCAR); MCS = metal-chelating substance; PAO = pheide a oxygenase; $\mathrm{pFCC}=$ primary bluefluorescent chlorophyll catabolite; Pheide $\mathrm{a}=$ pheophorbide $\mathrm{a} ; \mathrm{PPH}=$ pheophytinase; $\mathrm{RCCR}=$ red chlorophyll catabolite reductase. plants changed their photosynthetic capacity in the process of adapting to stress.

Foliar color changes are caused directly by shifts in the relative proportions of pigments, particularly the relative proportions of chlorophyll $\mathrm{b}$ and anthocyanin. Carotenoids have a role in plant responses to $\mathrm{TiO}_{2}$ stress, but this was not expressed in foliar color change; large changes in the relative proportions of carotenoid were not associated with changes in leaf color. The relative proportion of anthocyanin was small in $S$. rubrotinctum, but small changes in this relative proportion can result in large changes in leaf color. Although Ag-treated plants had attractive colors, they lost leaves and, hence, some of their ornamental value.

The chlorophyll content in plants usually declines with rising temperatures. Thus, decreased chlorophyll concentrations in the control and Sg-treated plants over the course of the experiment may have been due to rising temperatures in April and May.

\section{Conclusions}

We examined the effects of $\mathrm{Sg}$ and $\mathrm{Ag}$ applications on S. rubrotinctum plants. Sg did not significantly change leaf color, but enhanced plant growth, an effect that should be of great importance in commercial production and trade.

$\mathrm{Ag}$ enhanced anthocyanin production as a stress response. The leaf color change induced by Ag was rapid, which improved the plant's ornamental value. However, the quantity of Ag applied in this study appeared to exceed the tolerance of some of the plants, resulting in defoliation, growth stunting, and even death. Different concentrations of $\mathrm{Ag}$ and $\mathrm{Sg}$ should be tested to obtain a better balance of leaf color and plant growth. Combining $\mathrm{TiO}_{2}$ application with nutrient supplementation may strengthen the stress tolerance in plants. Cultivation conditions, secondary metabolism, and pigment synthesis pathways could be manipulated to improve the expression of genes related to anthocyanin synthesis.

\section{Literature Cited}

Abbott, J.A. 1999. Quality measurement of fruit and vegetables. Postharvest Biol. Technol. 15:207-225.

Agrawal, S. and P. Rathore. 2014. Nanotechnology pros and cons to agriculture: A review. Intl. J. Curr. Microbiol. Appl. Sci. 3(3):43-55.

Aliabadi, T., A.S. Afsharand, and F.S. Nematpour 2016. The effects of Nano $\mathrm{TiO}_{2}$ and Nano aluminium on the growth and some physiological parameters of wheat (Triticum aestivum). Indian J. Plant. Physiol. 6(2):1627-1635.

Armstrong, G.A. and J.E. Hearst. 1996. Carotenoids 2: Genetics and molecular biology of carotenoid pigment biosynthesis. FASEB J. 10(2): 228-237.

Aslani, F., S. Bagheri, N. Muhd Julkapli, A.S. Juraimi, F.S.G. Hashemi, and A. Baghdadi. 2014. Effects of engineered nanomaterials on plants growth: An overview. Sci. World J. 2014:641-759.

Balazadeh, S. 2014. Stay-green not always stays green. Mol. Plant 7(7):1264-1266.
Bartwal, A., R. Mall, P. Lohani, S.K. Guru, and S. Arora. 2013. Role of secondary metabolites and brassinosteroids in plant defense against environmental stress. J. Plant Growth Regul. 32:216-232.

Chalker-Scott, L. 1999. Environmental significance of anthocyanin in plant stress responses. Photochem. Photobiol. 70:1-9.

Cui, H.X., J.F. Jiang, P. Zhang, W. Gu, and Q. Liu. 2010. Application of Nano- $\mathrm{TiO}_{2} \mathrm{Sol}$ in crop diseases control. Eur. Cell. Mater. 20:293.

Dixon, R.A. and N. Paiva. 1995. Stressed induced phenyl propanoid metabolism. Plant Cell 7:1085-1097.

Dodd, I.C., C. Critchley, G.S. Woodall, and G.R. Stewart. 1998. Photoinhibition in differently colored juvenile leaves of Syzygium species. J. Expt. Bot. 49:1437-1445.

Edreva, A., V. Velilkova, T. Tsonev, S. Dagnon, A. Gürel, L. Aktaş, and E. Gesheva. 2008. Stressprotective role of secondary metabolites: Diversity of functions and mechanisms. Gen. Appl. Plant Physiol. 34:67-78.

Forney, C.F., M.A. Jordan, K.U.K.G. Nicholas, and J.R. DeEll. 2000. Volatile emissions and chlorophyll fluorescence as indicators of freezing injury in apple fruit. HortScience 35: 1283-1287.

Hu, D.G., C.H. Sun, Q.Y. Zhang, J.P. An, C.X You, and Y.J. Hao. 2016. Glucose sensor MdHXK1 phosphorylates and stabilizes MdbHLH3 to promote anthocyanin biosynthesis in apple. PLoS Genet. 12(8):E1006273

Hu, W.R., S.Q. Zhang, and Z.L. Ji. 2004. Study on acid treatment effects on pericarp color and physiological characteristics of Litchi fruit. Food Sci. 25(7):176-180.

Kumar, S., G. Bhanjana, A. Sharma, M.C. Sidhu, and N. Dilbaghi. 2014. Synthesis, characterization and on field evaluation of pesticide loaded sodium alginate nanoparticles. Carbohydr. Polym. 101:1061-1067.

Li, G.Z. 2011. Intimate coupled photocatalysis and biodegradation on a novel $\mathrm{TiO}_{2}$-coated biofilm carrier. Arizona State University, State of Arizona, MS Diss. Abstr.

Lichtenthaler, H.K. and A.R. Wellburn. 1983. Determinations of total carotenoids and chlorophylls $\mathrm{a}$ and $\mathrm{b}$ of leaf extracts in different solvents. Biochem. Soc. Trans. 11: 591-592.

McGivney, E., L.C. Han, A. Avellan, J. Vanbriesen, and K.B. Gregory. 2017. Disruption of autolysis in Bacillus subtilis using $\mathrm{TiO}_{2}$ nanoparticles. Sci. Rpt. 7:44308.

Ouzounis, T., E. Rosenqvist, and C.O. Ottosen. 2015. Spectral effects of artificial light on plant physiology and secondary metabolism: A review. HortScience 50:1128-1135.

Park, S.Y., J.W. Chung, S.Y. Soh, and S.Y. Nam. 2015. Effect of several supplemental lighting on growth of Crassula ovata in winter seas. Flower Res. J. 23(2):86-91.

Seigler, D.S. 1998. Plant secondary metabolism. Chapman and Hall (Kluwer Academic Publishers), Boston, MA.

Shah, M.P. 2013. Combined application of biological-photocatalytic process in degradation of reactive black dye: An excellent outcome. Afr. J. Microbiol. Res. 1(4): 92-97.

Shang, Y., J. Venail, S. Mackay, P.C. Bailey, K.E. Schwinn, P.E. Jameson, C.R. Martin, and K.M. Davies. 2011. The molecular basis for venation patterning of pigmentation and its effect on pollinator attraction in flowers of Antirrhinum. New Phytol. 189:602615 . 
Von Wettstein, D., S. Gough, and C.G. Kannangara. 1995. Chlorophyll biosynthesis. Plant Cell 7 (7):1039-1057.

Wang, Q.J., X.L. Che, and L. Wang. 2008. Dynamic changes of anthocyanin and the relevant biosynthesis enzymes in Padus virginiana 'Schubert' leaves. Linye Kexue 44(3): 45-49.
Wahid, A. 2007. Physiological implications of metabolite biosynthesis for net assimilation and heat-stress tolerance of Sugarcane (Saccharum officinarum) sprouts. J. Plant Res. 120(2):219-228.

Winkel-Shirley, B. 2001. Flavonoid biosynthesis: A colorful model for genetics, biochemistry, cell biology and biotechnology. Plant Physiol. 26:485-493.
Xu, D.Q. 2013. Photosynthesis. 1st ed. Science Press, Beijing, China.

Yu, X.L. 2010. Phytotoxicity of several typical engineered nanoparticles, Ocean University of China. Qingdao, China, MS Diss. Abstr.

Zhang, Y., E. Butelli, and C. Martin. 2014. Engineering anthocyanin biosynthesis in plants. Curr. Opin. Plant Biol. 19:81-90. 